\title{
Effect of the gap height between the vibration plate and heating surface on boiling heat transfer in a boiling bubble resonator
}

\author{
Noriyuki UNNO*, Kazuhisa YUKI*, Jun TANIGUCHI** and Shin-ichi SATAKE** \\ * Department of Mechanical Engineering, Sanyo-Onoda City University \\ 1-1-1 Daigakudo-ri, Sanyo-Onoda, Yamaguchi, 756-0884 Japan \\ ** Department of Applied Electronics, Tokyo University of Science \\ 6-3-1 Niijuku, Katsushika-ku, Tokyo 125-8585 Japan \\ E-mail: satake@te.noda.tus.ac.jp
}

Received: 24 August 2020; Revised: 12 October 2020; Accepted: 17 December 2020

\begin{abstract}
For boiling heat transfer, it is important to improve both the critical heat flux and heat transfer coefficient. In general, the heat transfer coefficient is improved by promoting the nucleation of boiling bubbles on the heating surface. However, this decreases the critical heat flux. To improve the heat transfer coefficient without decreasing the critical heat flux, we previously developed a technique using a boiling bubble resonator, which consists of a material attached close to the heating surface that vibrates in response to the growth and collapse of boiling bubbles. In this study, we used spacer plates to vary the gap height between the heating surface and boiling bubble resonator to maximize the boiling heat transfer. By optimizing the gap height, the wall superheat decreased by 7 and $25 \mathrm{~K}$ at 0.8 and $5.6 \mathrm{MW} / \mathrm{m}^{2}$, respectively. The maximum heat flux was $5.8 \mathrm{MW} / \mathrm{m}^{2}$ with the optimized gap height. In addition, we observed sound signals when the boiling bubble resonator was optimally vibrating. Moreover, jet flow from the gap appeared with the vibration of the boiling bubble resonator.
\end{abstract}

Keywords : Boiling heat transfer, Boiling bubble resonator, Self-excited vibration, FFT analysis

\section{Introduction}

Boiling heat transfer (BHT) involving phase-change phenomena has been studied for cooling with a high heat flux. In particular, pool boiling is considered to be an eco-friendly cooling technique because it only uses a natural force (the buoyancy of boiling bubbles), while eliminating the need for external elements to drive it, such as pumps or electric power. To evaluate the performance of BHT, the critical heat flux (CHF) and heat transfer coefficient (HTC) are commonly used.

The CHF is a key factor used for designing cooling devices with maximum heat flux. When the applied heat flux on a heating surface exceeds the CHF, the boiling state transitions from nucleate boiling to film boiling. The use of nucleate boiling is necessary to remove high heat flux. This is particularly important for power semiconductors, the heat-resistant temperature threshold of which is much lower than the surface temperature in film boiling. To achieve a suitable safety margin, it is necessary to improve the CHF. Surface modification is widely used to improve the CHF (Liang and Mudawar, 2019). For this purpose, nanostructures are typically used to increase the wetting limit temperature; that is, the nanostructure's capillary force prevents the thin liquid film on the heating surface from drying because of the liquid's phase change. In this context, relationships between the wickability and CHF have been explored (Rahman et al., 2014).

The lifetime of electronics, including power semiconductors, strongly depends on the operating temperature. Thus, an improved HTC is important for electronics that operate at low temperature. To improve the HTC, hydrophobic and hydrophilic patterns on a heating surface have been commonly investigated to control the wettability of the local surface (Betz et al., 2010). This is because the surface wettability of the heating surface is strongly associated with the behavior of boiling bubbles, such as bubble growth and detachment from the surface (Phan et al., 2009). 
A limitation of the aforementioned methods is their requirement for surface patterning on the heating surface. In particular, nanostructures are needed in most situations. However, it is difficult to simultaneously enhance the CHF and HTC using a uniform nanostructure on the heating surface. This is because the HTC is usually improved by promoting the nucleation of boiling bubbles on the heating surface, which tends to decrease the CHF (Hsu and Chen, 2012). Therefore, localized nanostructures (Rahman and McCarthy, 2017) and hierarchically structured surfaces (Chu et al., 2013) have been fabricated on heating surfaces to simultaneously improve the CHF and HTC. In addition, inversion of the boiling curve (Jaikumar and Kandlikar, 2017) has been achieved by controlling the behavior of boiling bubbles by separating nucleating regions and the paths of liquid supply (Kandlikar, 2017). Various methods have been used to fabricate localized nanostructures or wettability patterns, including micro-electro mechanical systems (MEMS) techniques (Chu et al., 2012), laser surface treatment (Kumar et al., 2020), and chemical etching (Kim et al., 2011) and plating (Sinha-Ray et al., 2011). However, the equipment required for MEMS and laser systems is expensive, and the environmental impact and disposal costs of the chemicals used in these methods are high. Thus, a new technology that is inexpensive and eco-friendly is needed to simultaneously enhance the CHF and HTC.

Boiling heat transfer in a confined space was studied at saturated boiling (Katto and Yokoya, 1966; Fujita et al., 1988), whereby an interference plate was positioned against a heating surface with a gap. These papers reported that confinement of the boiling space increases the HTC at low heat flux because the confined space facilitates the generation of boiling bubbles by maintaining a superheated layer. However, the confined space also promotes bubble coalescence, resulting in a lower CHF. To prevent the decrease of the CHF, mesh screens have been used to allow the boiling bubbles to easily escape (Zhao et al., 2003). A different approach to enhance heat transfer, including boiling heat transfer, is to apply ultrasound (Legay et al., 2011). However, this requires an external power source and thus consumes electric energy. Moreover, if electric energy can be supplied, it is simpler to use pumps than ultrasound.

To further improve the HTC without decreasing the CHF, we recently developed a technique using a boiling bubble resonator (BBR), which is a vibration material attached close to the heating surface (Unno et al., 2020). The BBR is selfexcited by the growth and collapse of boiling bubbles, which results in continuous vibration with no applied external forces. In that previous study, a thin brass plate (width of $10 \mathrm{~mm}$, thickness of $100 \mu \mathrm{m}$, length of $10 \mathrm{~mm}$ ) was used as the BBR. Jet flow was generated in one direction at the heating surface because of the BBR's continuous vibration. Because this vibration and flow push large coalesced bubbles away from the heating surface, the HTC can be increased without decreasing the $\mathrm{CHF}$ at the designed heat flux. In addition, our previous study revealed that a rigid plate without vibration decreases the CHF.

In this study, we investigated the boiling heat transfer for various gap heights between the heating surface and the BBR because the behavior of boiling bubbles in the gap affects the jet flow. The jet flow will become weaker when the vibration material is far from the heating surface. Conversely, when the gap height is too small, it is difficult to supply the subcooled liquid to the heating surface through the gap. Thus, we performed subcooled pool boiling with the BBR set at different gap heights. In this study, we used spacer plates to vary the gap height between the heating surface and BBR. To gain insight into the mechanism of the BBR, we also analyzed the sound emission. Previously, boiling sound has been studied in subcooled pool boiling (Tang, 2018), including the microbubble emission boiling (MEB) regime (Inada et al., 1981). These studies reported that the bubble lifetime decreased with increasing wall superheat, whereas the bubble size barely changed. This leads to a higher acoustic energy in the low-frequency range. Therefore, an aim of the present study was to establish design guidelines for a BBR system using the measured boiling sound.

\section{Materials and methods}

\subsection{Experimental apparatus}

Figure 1 shows the experimental setup for subcooled pool boiling using a BBR. The side walls of a test vessel were made of four heat-resistant glass plates that were $5 \mathrm{~mm}$ thick, $200 \mathrm{~mm}$ wide, and $200 \mathrm{~mm}$ high. The four glass plates were bonded on each side and used as the side frame walls of the test vessel. Silicon rubber sheets were placed between the glass frame walls and a top cover, and between the frame walls and a lower stainless-steel plate (hereinafter referred to as "bottom plate"). The pool vessel was assembled by fastening bolts through these parts. De-ionized water was used as the working fluid and the test vessel was filled to $150 \mathrm{~mm}$ with the water. In this study, the water was degassed by boiling using two auxiliary pipe heaters in the test vessel. A heat exchanger made from a copper pipe was installed in the 
test vessel and coolant from a chiller was circulated in the heat exchanger. The water temperature in the test vessel was kept at $50{ }^{\circ} \mathrm{C}$ (that is, liquid subcooling of $50 \mathrm{~K}$ ) using the heat exchanger and the auxiliary heaters. The experiments were carried out at atmospheric pressure because the test vessel was not a closed container.

An oxygen-free copper heating block was installed at the center of the bottom plate. The thickness of the bottom plate around the heating block was $0.5 \mathrm{~mm}$ to suppress heat leakage from the heating block to the plate. The heating block comprised a cylindrical upper part and a heating part with cartridge heaters. The top of the heating block was exposed to the inside of the pool and the diameter of the heating surface was $9 \mathrm{~mm}$. The gap between the bottom plate and the heating surface was sealed using room-temperature vulcanizing silicone. The cylindrical upper part contained three K-type thermocouples at distances of 3,6 and $9 \mathrm{~mm}$ from the heating surface. Using these thermocouples, the temperature distribution was measured along the center axis of the cylindrical part and recorded using a data logger; the temperature of the water in the pool was also monitored using a K-type thermocouple at a height of $1 \mathrm{~cm}$ from the bottom plate. First, the applied voltage supplied to the cartridge heaters was increased to $20 \mathrm{~V}$ for the onset of initiate boiling. Then, the voltage was increased in $5-\mathrm{V}$ increments to control the heat flux of the heat transfer surface. The heat flux and the wall superheat were calculated using the same method as described in our previous study (Unno et al., 2020), with the assumption that the temperature varies linearly between the values measured by the three thermocouples. In this study, CHF is defined as the maximum heat flux measured under steady-state conditions before the temperature rapidly increased to above $200{ }^{\circ} \mathrm{C}$. Figure 2 shows typical temperature distributions measured using the three thermocouples with and without the BBR. The coefficient of determination was greater than 0.999 in all cases. To prevent burning of the silicone sealing, we stopped the experiment when the temperature measured by the thermocouple at $3 \mathrm{~mm}$ reached $200{ }^{\circ} \mathrm{C}$. In addition, the boiling sound was recorded in air $5 \mathrm{~cm}$ from the glass vessel.

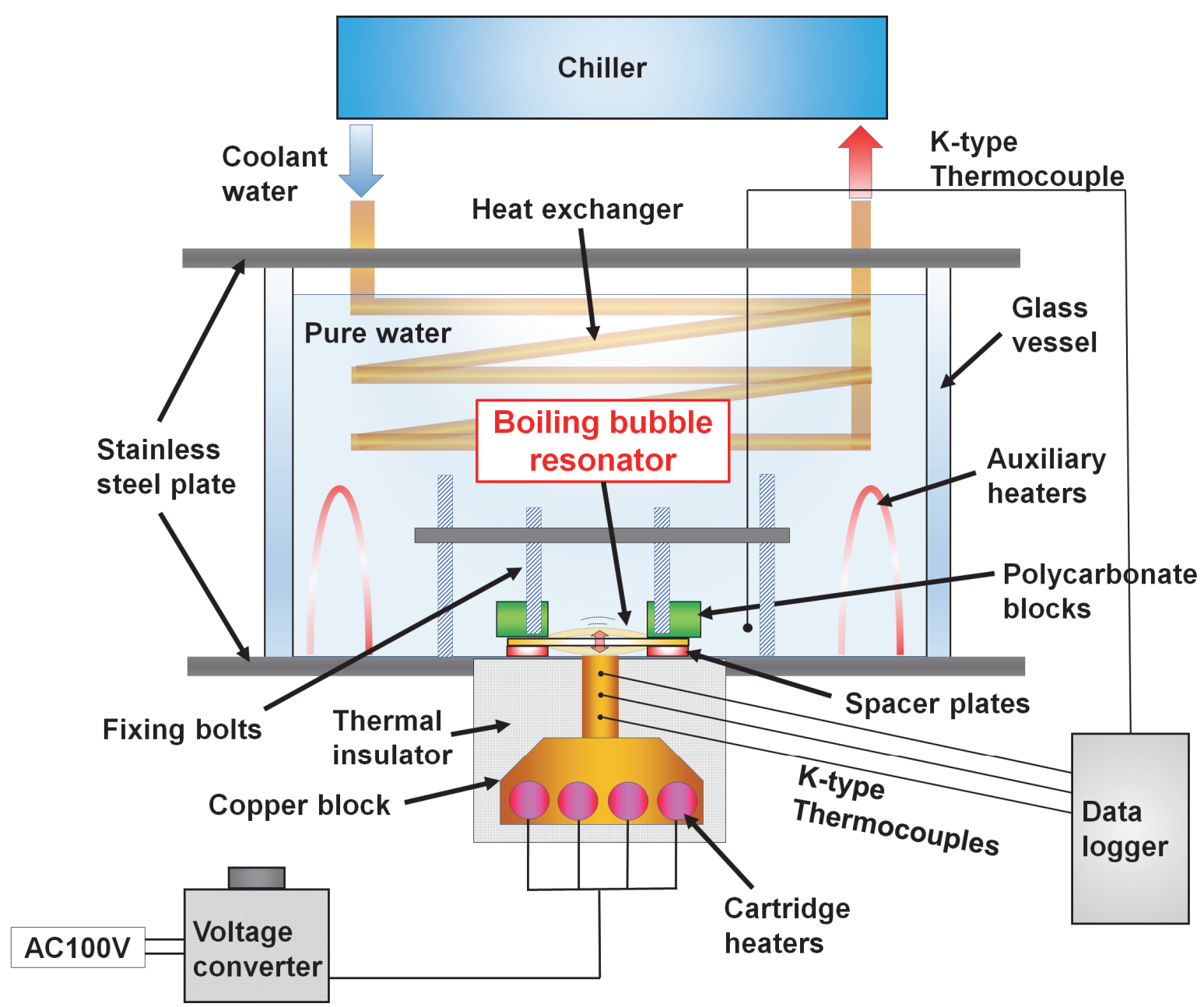

Fig. 1. Experimental setup for subcooled pool boiling using the boiling bubble resonator. 


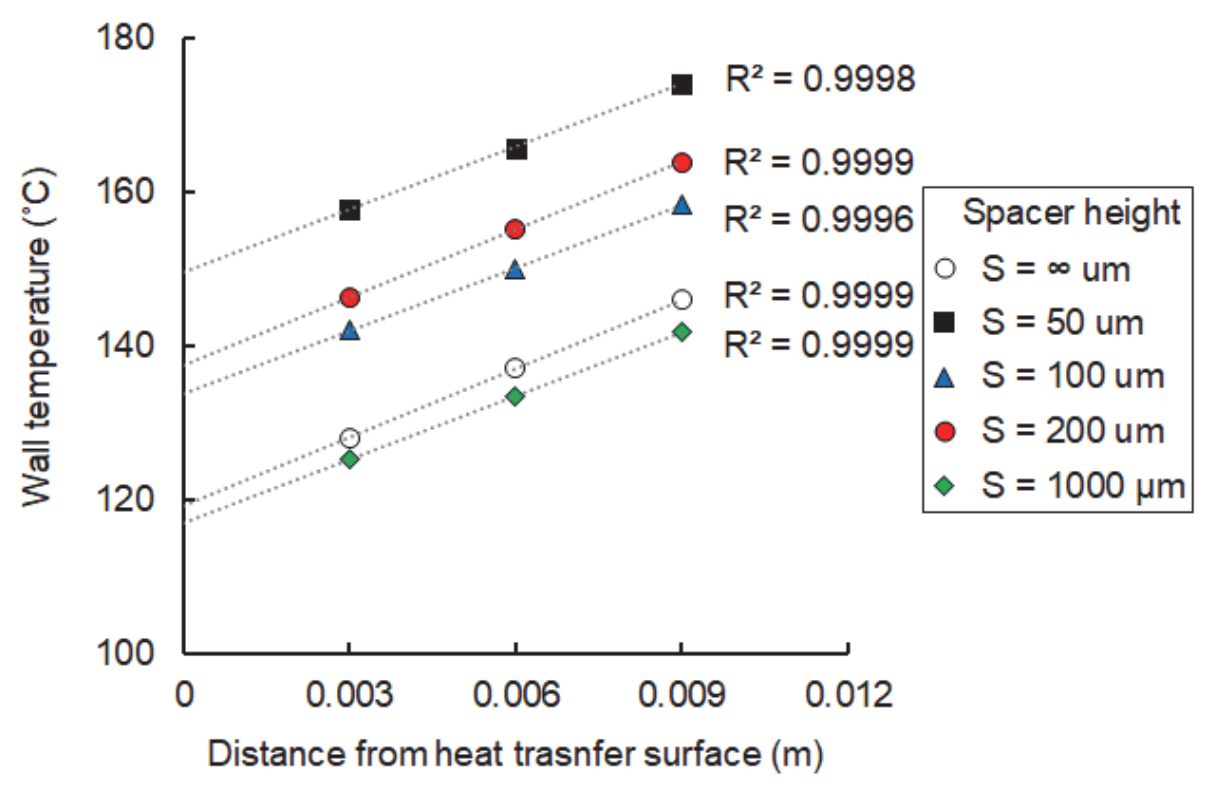

Fig. 2 Typical temperature distribution in the copper heating block with and without the BBR at approximately $1 \mathrm{MW} / \mathrm{m}^{2}$.

\subsection{Binding conditions of boiling bubble resonator}

Before the experiment, we analyzed the boiling sound without the BBR plate at a liquid subcooling of $50 \mathrm{~K}$, as shown in Fig. 3. In the nucleate boiling regime, there is a peak at $1101 \mathrm{~Hz}$ and the power of this peak is greater than that at 1664 Hz. We believe that the peak at $1101 \mathrm{~Hz}$ is related to the properties of the working fluid (i.e., water). Because this peak is close to the BBR operating frequency $(1180 \mathrm{~Hz})$, we used the operating frequency to determine $L$. We experimentally found this to be suitable for self-excited vibration in our previous study. The BBR was tightly fixed using fixing bolts to polycarbonate blocks at the edges. Therefore, the BBR was assumed to be a fixed beam at both ends, the length of which was calculated using the following equation (Clough and Penzien, 1975):

$$
L=\sqrt{\frac{\lambda^{2}}{2 \pi f} \sqrt{\frac{E I}{\rho A}}},
$$

where $\lambda$ is a constant that depends on the vibration mode, $f(\mathrm{~Hz})$ is the natural frequency, $E\left(\mathrm{~N} / \mathrm{m}^{2}\right)$ is the Young's modulus, $\rho\left(\mathrm{kg} / \mathrm{m}^{3}\right)$ is the material density, $I\left(\mathrm{~m}^{4}\right)$ is the area moment of inertia and $A\left(\mathrm{~m}^{2}\right)$ is the cross-sectional area. To design the BBR considering first-order vibration, $\lambda$ must be 4.730 . Here, the natural frequencies of BBRs with $L=$ $0.0170,0.0175$ and $0.0180 \mathrm{~m}$ are 1240,1170 and $1106 \mathrm{~Hz}$, respectively. Consequently, the length was set at $0.0175 \mathrm{~m}$.

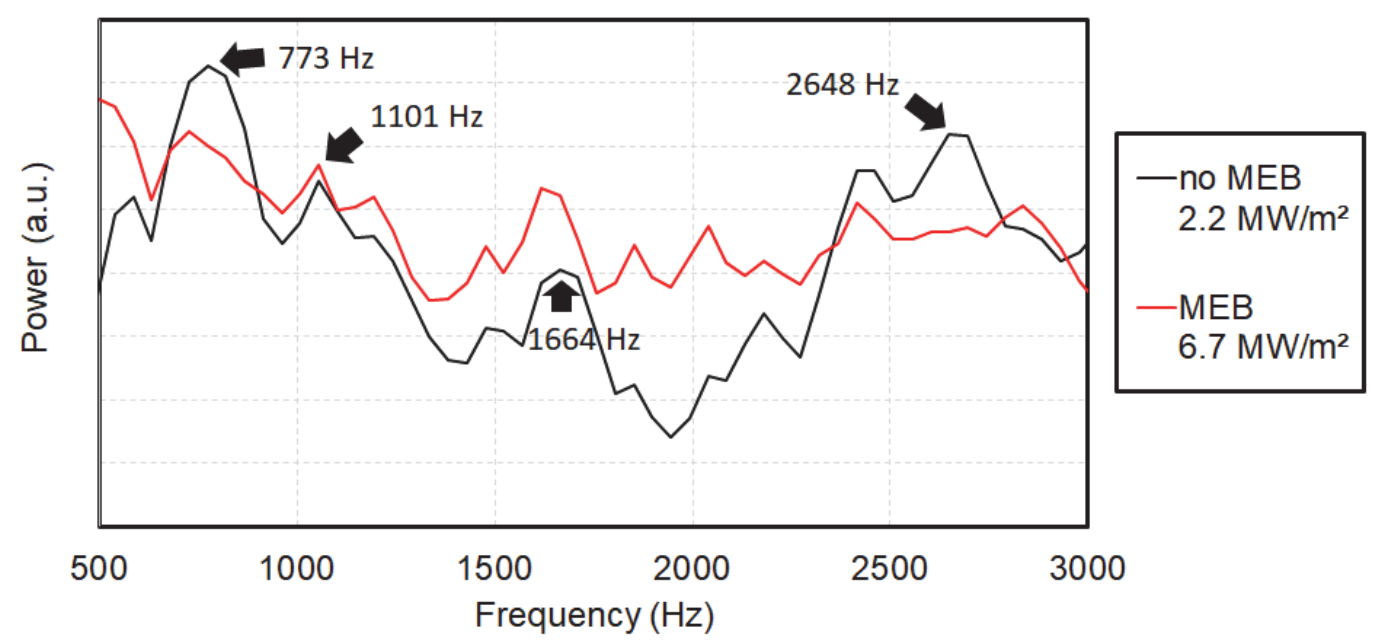

Fig. 3 FFT analysis of the boiling sound measured in air without the BBR plate at a liquid subcooling of $50 \mathrm{~K}$. 
A cross-section schematic view and a top view of the BBR are shown in Fig. 4(a and b), respectively. A thin brass plate was used as the BBR; its width, total length and thickness were $10 \mathrm{~mm}, 30 \mathrm{~mm}$ and $100 \mu \mathrm{m}$, respectively. This is the same size as used in our previous study (Unno et al., 2020). The vibrating length, $L(\mathrm{~m})$, was measured with a caliper and the edges of the brass plate were fixed by pressing against polycarbonate blocks. To create a gap between the brass plate and the heating surface, spacer plates were used, as shown in red in Fig. 4(a). Spacer plates with different heights were examined (50, 100, 200 and $1000 \mu \mathrm{m}$; Table 1). Figure 4(c) shows a photograph of a typical setup. The center of the heating surface was aligned as closely as possible with the center of the BBR. The width of the brass plate was 10 $\mathrm{mm}$, which was larger than the heating surface, the diameter of which was $9 \mathrm{~mm}$. Consequently, the heating surface appeared totally covered with the brass plate when viewed from above. However, as shown in Fig. 4(c), boiling bubbles and subcooled liquid pass through the gap.

Table 1 Gap heights used in this study.

\begin{tabular}{ll}
\hline Length, $L(\mathrm{~m})$ & Gap height, $S(\mu \mathrm{m})$ \\
\hline 0.0175 & 50 \\
0.0175 & 100 \\
0.0175 & 200 \\
0.0175 & 1000 \\
\hline
\end{tabular}

(a)

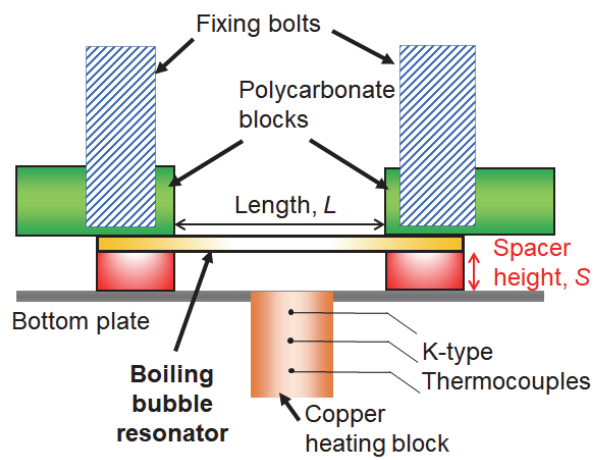

(b)

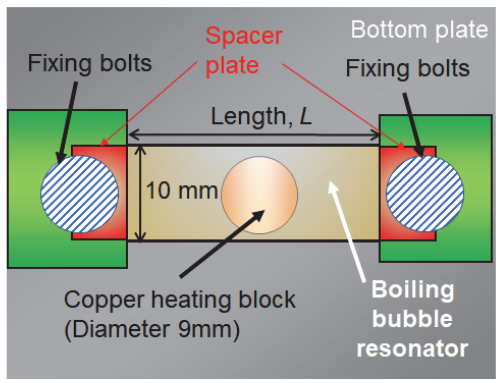

(c)

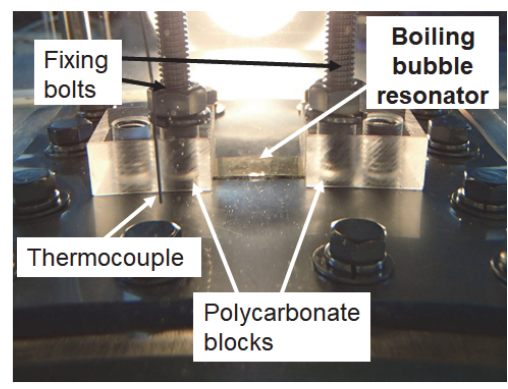

Fig. 4. Schematic illustrations of (a) the cross-section and (b) top view close to the copper heating surface. (c) Photograph of a typical setup using a thin brass plate as the boiling bubble resonator.

\section{Results and discussion}

Figure 5(a) shows the boiling curves for different spacer heights with a constant length of $0.0175 \mathrm{~m}$ at a liquid subcooling of $50 \mathrm{~K}$, and Figure 5(b) shows these HTCs as a function of the heat flux. The dotted line in Fig. 5(a) is the CHF in the subcooled pool boiling predicted using the Ivey-Morris correlation (Ivey and Morris, 1966) based on Zuber's prediction (Zuber, 1959). Kutateladze's correlation (Kutateladze, 1952) is also plotted (solid line), which is the correlation of the boiling heat transfer in the nucleate boiling regime. Each error bar represents the uncertainty of the heat flux and the wall superheat. The open circles are the boiling curve without the BBR. The slope of this curve changes when the heat flux exceeds the value of the Ivey-Morris correlation and MEB is observed above $5.6 \mathrm{MW} / \mathrm{m}^{2}$ (marked by the red, dashed circle). We note that the maximum heat flux is not the CHF because the experiment was intentionally stopped at this point to avoid burning of the silicone sealing. These results correspond to those of a previous study that included the MEB regime (Zhu et al., 2014). Using the same setup, subcooled pool boiling tests were carried out for different gap heights. 
(a)

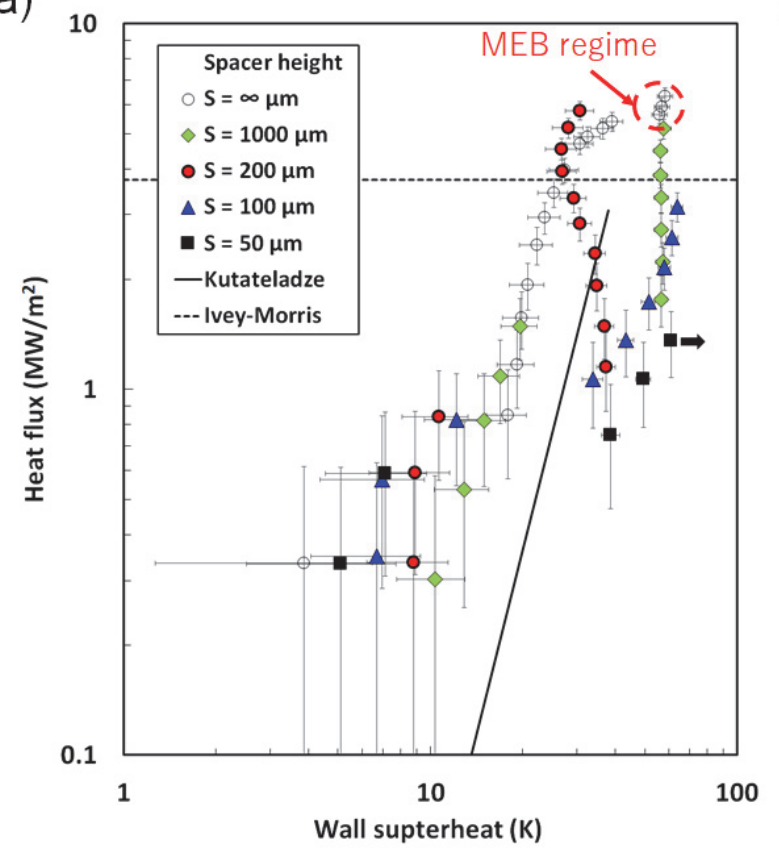

(b)

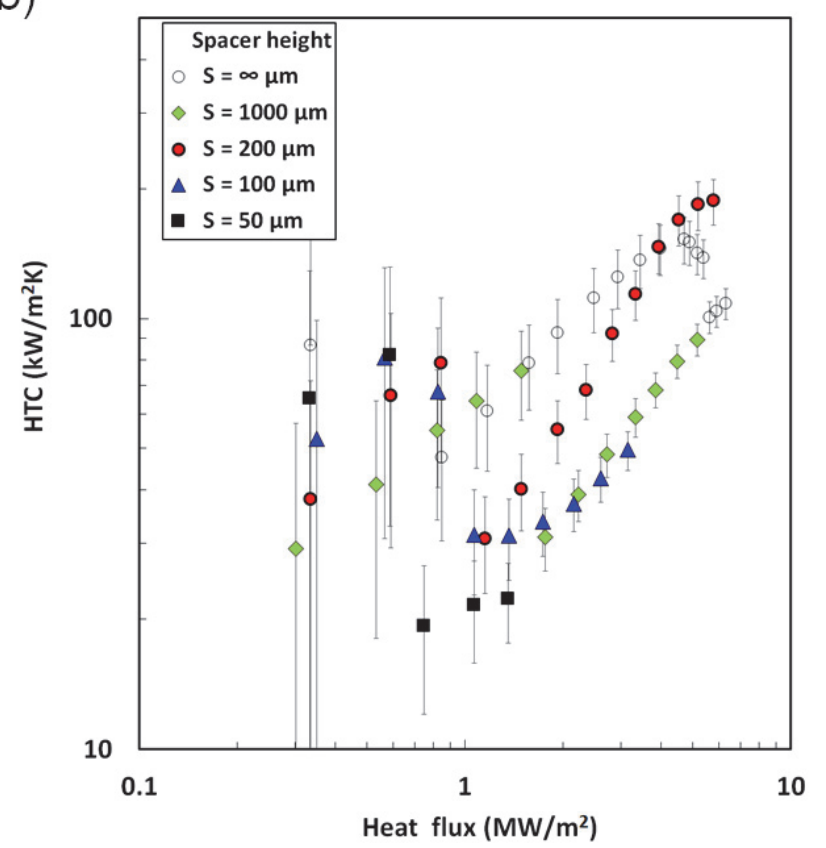

Fig. 5 (a) Boiling curves for different spacer heights, $S$, at a liquid subcooling temperature of $50 \mathrm{~K}$ (atmospheric pressure).

The length, $L$, is constant at $0.0175 \mathrm{~m}$. (b) HTC as a function of the heat flux.
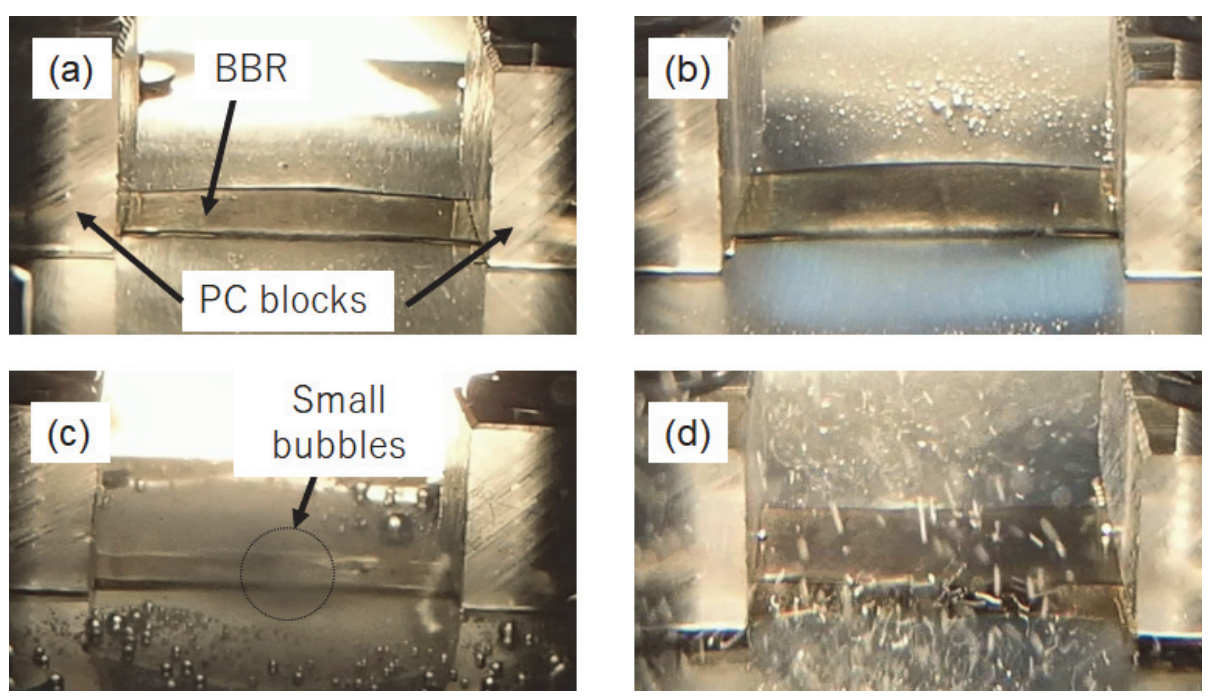

Fig. 6 Boiling bubble behavior for spacer heights of: (a) $50 \mu \mathrm{m}$ at $1.4 \mathrm{MW} / \mathrm{m}^{2}$, (b) $100 \mu \mathrm{m}$ at $3.1 \mathrm{MW} / \mathrm{m}^{2}$, (c) $200 \mu \mathrm{m}$ at $5.8 \mathrm{MW} / \mathrm{m}^{2}$ and (d) $1000 \mu \mathrm{m}$ at $5.2 \mathrm{MW} / \mathrm{m}^{2}$.

The boiling curve with a spacer height of $50 \mu \mathrm{m}$ is plotted with black squares in Fig. 5. In this case, the wall superheat was less than $10 \mathrm{~K}$ below $0.6 \mathrm{MW} / \mathrm{m}^{2}$ (these plots are also in the boiling regime) but increased to $39 \mathrm{~K}$ at $0.7 \mathrm{MW} / \mathrm{m}^{2}$. We consider that the gap was filled with vapor and that the heating surface was partly covered with vapor, which resulted in the formation of dry patches. The CHF was at $1.4 \mathrm{MW} / \mathrm{m}^{2}$ and film boiling was observed above this heat flux. Figure 6(a) shows the behavior of boiling bubbles at the CHF with a spacer height of $50 \mu \mathrm{m}$. The boiling bubbles were expanded under the brass plate and partially emerged from the gap. They then condensed upon contacting the subcooled liquid and produced sound. In this case, however, the wall superheat increased even though the brass plate was vibrated. This is because the vapor generated on the heating surface filled the gap. Therefore, condensation only occurred at the side edge of the BBR plate and subcooled liquid could not easily permeate into the gap and reach the heating surface. Consequently, the heating surface dried out because the amount of the permeated subcooled liquid was insufficient to remove the generated heat, and the CHF condition was reached. 
We repeated the subcooled pool boiling experiment with a spacer height of $100 \mu \mathrm{m}$, as shown by the solid blue triangles in Fig. 4. The wall superheat at $0.6 \mathrm{MW} / \mathrm{m}^{2}$ was almost the same as that with a spacer height of $50 \mu \mathrm{m}$, whereas at $0.8 \mathrm{MW} / \mathrm{m}^{2}$ it was lower. The wall superheat increased rapidly to $33 \mathrm{~K}$ at $1.1 \mathrm{MW} / \mathrm{m}^{2}$, above which it increased steadily with increasing heat flux. The experiment was stopped at $3.2 \mathrm{MW} / \mathrm{m}^{2}$ to avoid burning of the silicone sealing. Therefore, the maximum heat flux in this case was not the CHF. Figure 6(b) shows the behavior of the boiling bubbles at the maximum heat flux with a spacer height of $100 \mu \mathrm{m}$. These results indicate that the expected CHF for a spacer height of $100 \mu \mathrm{m}$ should be higher than for a spacer height of $50 \mu \mathrm{m}$, which we attribute to the subcooled liquid being supplied in a more continuous manner to the heating surface. Moreover, at $1.1 \mathrm{MW} / \mathrm{m}^{2}$, the wall superheat with a spacer height of $100 \mu \mathrm{m}$ was lower than that with a spacer height of $50 \mu \mathrm{m}$. These results indicate that the increase of the wall superheat was caused by the repeating contact between the BBR and other materials (the heating surface or the bottom plate) and/or by forming dry patches owing to the filling of vapor into the gap. Although the BBR was excited by the growth and collapse of boiling bubbles, removing large coalesced bubbles from the heating surface was difficult when the gap was narrow because the amplitude of vibration was restricted owing to interference. Therefore, these results reveal that the wall superheat does not decrease with a very narrow gap even with the BBR.

The data for subcooled pool boiling with a spacer height of $1000 \mu \mathrm{m}$ are shown in Fig. 5 as solid green diamonds. In this case, the wall superheat was the same as that without the BBR up to $1.5 \mathrm{MW} / \mathrm{m}^{2}$, then increased rapidly to $56 \mathrm{~K}$ at $1.8 \mathrm{MW} / \mathrm{m}^{2}$. This rapid increase might be due to the generation of dry patches on the heat transfer surface. Another explanation is the rapid increase in the wall temperature, which was observed in the transition to MEB without the BBR. We estimated the onset of MEB to be $1.8 \mathrm{MW} / \mathrm{m}^{2}$. In contrast to the boiling curves with spacer heights of 50 and 100 $\mu \mathrm{m}$, the wall superheat was almost constant from 1.8 to $5.2 \mathrm{MW} / \mathrm{m}^{2}$. This phenomenon has been reported as MEB in a narrow gap (Sakamoto et al., 2019). Film boiling was not observed, and the experiment was stopped at $5.2 \mathrm{MW} / \mathrm{m}^{2}$ to prevent burning of the silicone sealing. We had expected that MEB would also occur in the present study. Figure 6(d) shows the behavior of boiling bubbles at $5.2 \mathrm{MW} / \mathrm{m}^{2}$ with a spacer height of $1000 \mu \mathrm{m}$. Many microbubbles were emitted from the gap and the sound intensity was weaker than for spacer heights of 50 and $100 \mu \mathrm{m}$. The transition to MEB depends on the degree of liquid subcooling (Suzuki et al., 2011). Accordingly, a broad gap promotes MEB because it lowers the degree of liquid subcooling under the BBR plate and leads to the generation of large coalesced bubbles in the gap. During MEB, the expansion force of boiling bubbles allows them to escape from the gap to the water pool, which results in a small exciting force for the BBR. Consequently, the boiling curve with a spacer height of $1000 \mu \mathrm{m}$ in the MEB regime approaches the curve obtained without the BBR plate. Moreover, there was no decrease in the wall superheat close to the MEB regime when the spacer height was $1000 \mu \mathrm{m}$.

The boiling curve for a spacer height of $200 \mu \mathrm{m}$ is represented by the solid red circles in Fig. 5. At $1.2 \mathrm{MW} / \mathrm{m}^{2}$, the wall superheat rapidly increased, which is similar to the case with a spacer height of $100 \mu \mathrm{m}$. However, further increasing the heat flux led to a negative slope of the boiling curve and a decrease in the wall superheat. Moreover, there is an inflection point at $4.5 \mathrm{MW} / \mathrm{m}^{2}$, above which the slope of the boiling curve turns again to positive. When the heat flux was $5.8 \mathrm{MW} / \mathrm{m}^{2}$, the wall superheat was $31 \mathrm{~K}$ using the BBR. This means that the wall superheat with the BBR decreased by $25 \mathrm{~K}$ compared with that without the BBR in MEB $(56 \mathrm{~K})$. However, the temperature rise before the vibration of the BBR is unfavorable. To prevent the formation of dry patches without influencing the BBR, a new approach should be developed in the future. Figure 6(c) shows the behavior of boiling bubbles and the BBR at $5.8 \mathrm{MW} / \mathrm{m}^{2}$ with a spacer height of $200 \mu \mathrm{m}$. Some bubbles were observed on the bottom plate; however, these were not boiling bubbles generated on the bottom plate and did not affect the BHT. In this case, the BBR vibrated intensely with high sound intensity while emitting many small bubbles from the gap. In addition, jet flow was observed at the opening of the gap, as shown in Fig. 7. Upon further increase of the heat flux, the wall superheat gradually increased. The experiment was stopped before steady-state conditions were reached because of the temperature limit. Ultimately, these experimental results allow us to propose two key guidelines for designing a BBR. The first is that the BBR plate should be close to the heating surface to receive the expansion force of the boiling bubbles. We note that the BBR plate did not decrease the wall superheat at high heat flux, as we demonstrated for a spacer height of $1000 \mu \mathrm{m}$. The second is that the BBR plate needs a sufficient gap height to avoid contact with other materials, such as the bottom plate. As noted in the case of a spacer height of $50 \mu \mathrm{m}$, the CHF is drastically decreased when the BBR plate is close to the heating surface. 


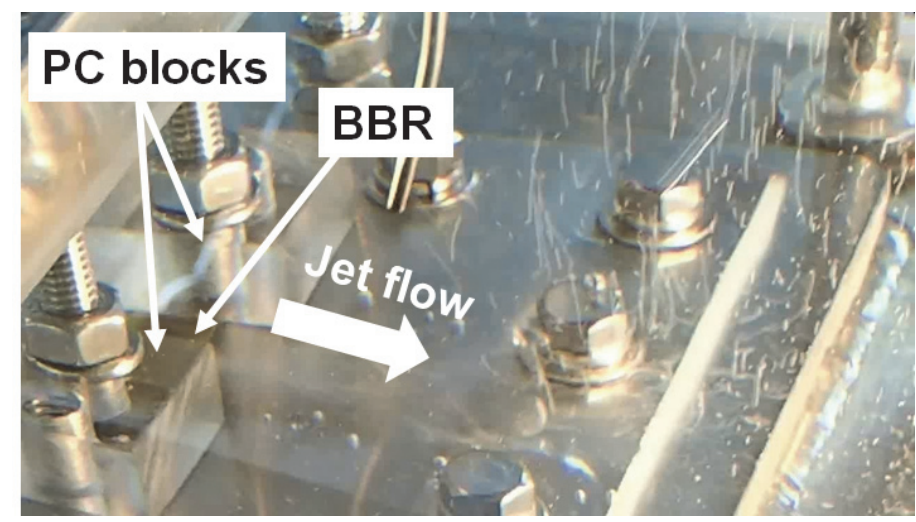

Fig. 7. Jet flow observed between the boiling bubble resonator and the heating surface.

We also analyzed the acoustic signal form the BRR vibration in air using the fast Fourier transform (FFT) method in Wavesurfer (Sjölander and Beskow, 2000). Figure 8 shows the FFT results for different heat fluxes. We note that the vertical axis shows the normalized power intensity; therefore, the intensities cannot be directly compared across difference experiments. For a spacer height of $200 \mu \mathrm{m}$, the sound field was focused because this was the optimum height for the BBR in our study to decrease the wall superheat (Fig. 8(c)). When the heat flux was below $0.8 \mathrm{MW} / \mathrm{m}^{2}$, there was no peak in the range $800-1000 \mathrm{~Hz}$. However, there was a clear peak at $773 \mathrm{~Hz}$ at $1.2 \mathrm{MW} / \mathrm{m}^{2}$ due to the intermittent vibration of the BBR. The wall superheat also rapidly increased at $1.2 \mathrm{MW} / \mathrm{m}^{2}$ under these conditions, as mentioned earlier. This is because isolated boiling bubbles on the heating surface grew and collapsed in the gap at the lower heat flux, whereas they coalesced in the gap at higher heat flux, resulting in a higher wall superheat. Under these conditions, large coalesced bubbles push upon the brass plate and cause the BBR to vibrate.

(a)

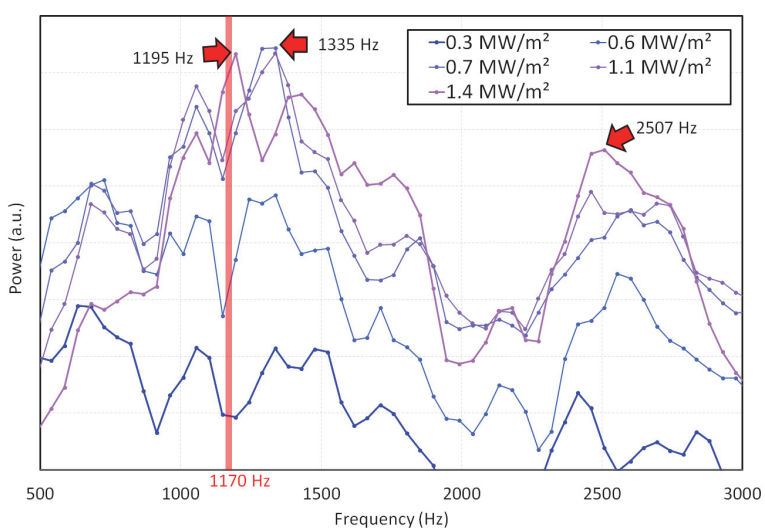

(c)

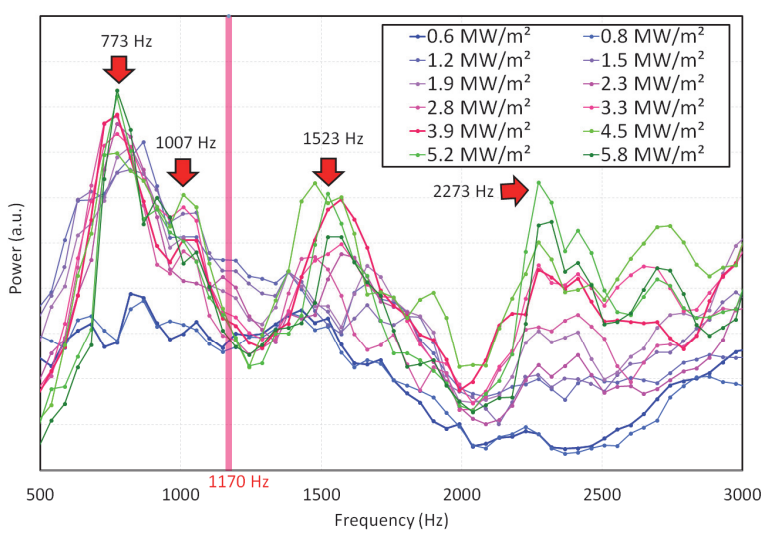

(b)

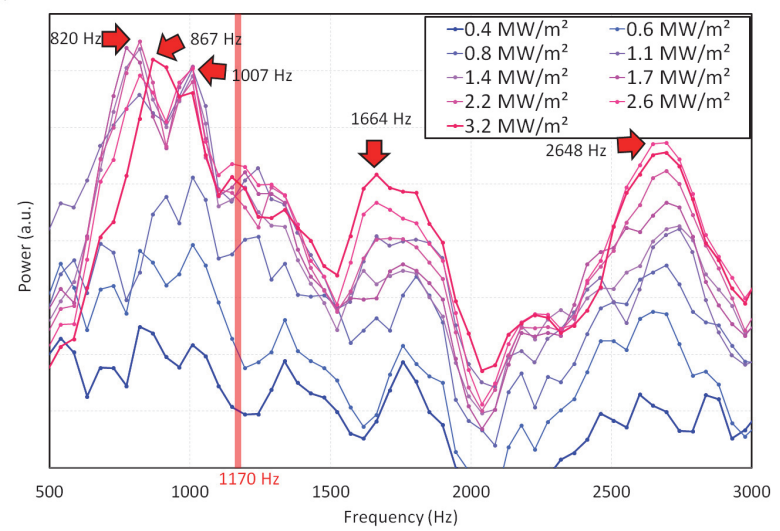

(d)

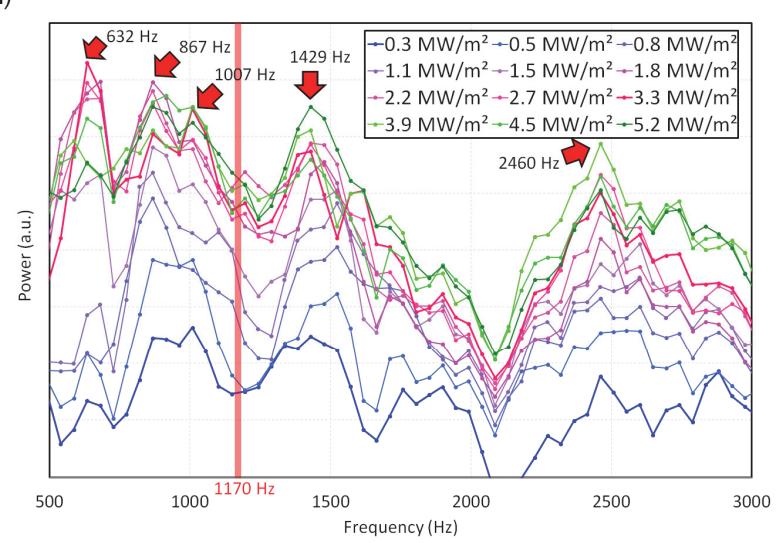

Fig. 8 FFT analysis of the boiling sound measured in air for spacer heights of: (a) $50 \mu \mathrm{m}$, (b) $100 \mu \mathrm{m}$, (c) $200 \mu \mathrm{m}$ and (d) $1000 \mu \mathrm{m}$. 
For a spacer height of $200 \mu \mathrm{m}$, the lowest-frequency peak was found at $773 \mathrm{~Hz}$ and the second and third peaks were approximately double and triple the frequency of the lowest peak, respectively. A clean sinusoidal wave produces only one peak in the FFT spectrum, whereas a triangular or square wave contains higher-order harmonics. In addition, even harmonics are observed when the input sound signal is asymmetrical (Smith, 1997). Thus, in our system, the main sound frequency was $773 \mathrm{~Hz}$. However, the operating frequency of the BBR used in this study was $1170 \mathrm{~Hz}$; thus, there was a difference of 300-400 $\mathrm{Hz}$ between the operating and observed frequency. We suggest that the observed sound was probably caused by the collapse of boiling bubbles due to the subcooled condition. On the other hand, there was a small peak at $1007 \mathrm{~Hz}$ : it is not clear if this is related to the vibration of the BBR. Nevertheless, these results explain the increase in HTC. Specifically, we suggest that if the BBR plate is vibrated at its resonance frequency, boiling bubbles generated at a lower frequency than the resonance frequency are quickly removed with the supply of fresh subcooled liquid to the heating surface. This interpretation is consistent with the peak of $1007 \mathrm{~Hz}$ decreasing above $4.5 \mathrm{MW} / \mathrm{m}^{2}$, which is the inflection point in the boiling curve.

Figure 8(a) shows the FFT results for a spacer height of $50 \mu \mathrm{m}$. The lowest-frequency peak appeared at 1200-1300 $\mathrm{Hz}$, which is closer to the operating frequency of the BBR than the frequency observed for the other spacer heights. However, it is possible that the BBR contacted the bottom plate and/or there was a change in the rate of bubble growth via coalescence in the narrow gap. Therefore, further experiments are needed to clarify the reason for the frequency shift in contrast with other spacer heights. The wall superheat did not decrease with the BBR under these conditions.

(a)

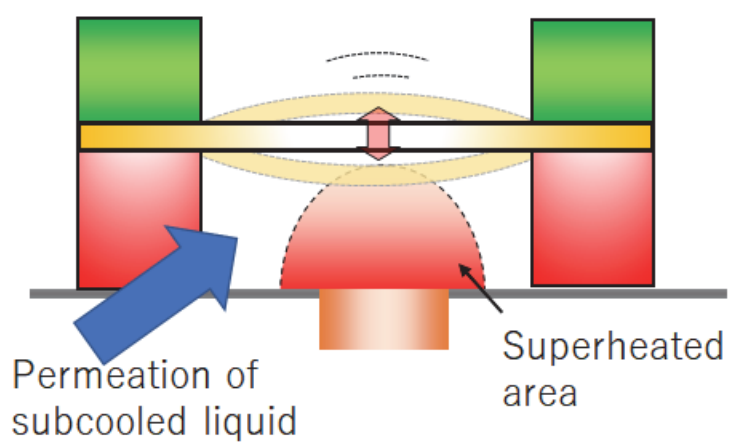

(b)

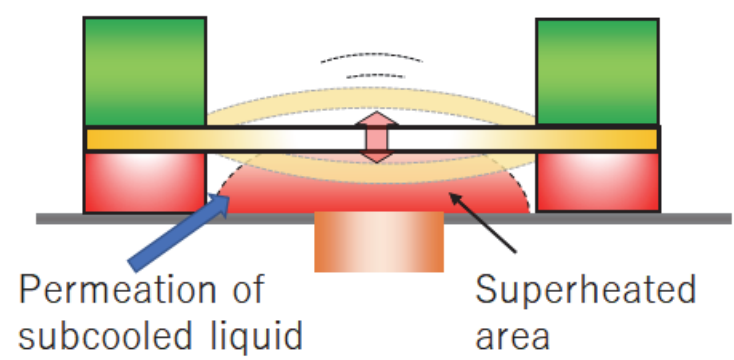

Fig. 9 Schematic illustration of the cross-section of the BBR just after large coalesced bubbles were pushed away with (a) a wider-gap BBR and (b) a narrower-gap BBR at the same heat flux.

Figure 8(b) shows the FFT results for a spacer height of $100 \mu \mathrm{m}$. The lowest-frequency peak appeared at $820 \mathrm{~Hz}$, which is higher than that for a spacer height of $200 \mu \mathrm{m}(773 \mathrm{~Hz})$. This is because the superheated liquid layer grows more easily in a narrower gap for a given heat flux because of the restricted boiling space. Figure 9 shows a schematic illustration just after large coalesced bubbles were pushed away from the heating surface by the vibration of the BBR. At this time, the boiling bubble nuclei might be deactivated because the highly subcooled liquid penetrates inside the gap, and because a superheated layer may exist under the gap until new bubbles are generated. However, it is more difficult for subcooled liquid to permeate through a narrower gap. Consequently, the frequency increases with decreasing bubble waiting time. It is noteworthy that the peak shifted to $867 \mathrm{~Hz}$ when the heat flux reached $3.2 \mathrm{MW} / \mathrm{m}^{2}$. The wall superheat gradually increased after further increasing the heat flux. Accordingly, we assume that the growth and collapse frequency of the boiling bubbles deviated from the natural frequency of the BBR. This is because a higher heat flux affects the supply of subcooled liquid, which results in a change in the growth and collapse frequency of the boiling bubbles.

Figure 8(d) shows the FFT results for a spacer height of $1000 \mu \mathrm{m}$. The difference between this case and those for other heights is the presence of a peak at $630 \mathrm{~Hz}$ when the heat flux exceeded $1.8 \mathrm{MW} / \mathrm{m}^{2}$. The emergence of this peak coincided with the rise in wall superheat to $57 \mathrm{~K}$. This indicates the presence of large coalesced bubbles in the gap, the collapse of which probably produced this peak. In addition, the maximum peak at $5.2 \mathrm{MW} / \mathrm{m}^{2}$ appeared at $1429 \mathrm{~Hz}$, which is similar to that observed for MEB in a previous study (Kawakami et al., 2019). 
Figure 10 shows the raw sound signals for a spacer height of $200 \mu \mathrm{m}$ at each heat flux. The horizontal axis is time and the vertical axis is the amplitude of the sound signal. For a heat flux of 2.3 or $3.3 \mathrm{MW} / \mathrm{m}^{2}$, the jet flow disappeared, as indicated by the white arrows. At this time, the BBR might be intermittently stopped. Furthermore, the quiescent time of the BBR at $3.3 \mathrm{MW} / \mathrm{m}^{2}$ was shorter than at $2.3 \mathrm{MW} / \mathrm{m}^{2}$. This is because the time required for bubbles to initiate and coalesce, which takes place during the heating of the liquid in the gap (namely, the bubble waiting time), is shorter at higher heat flux. A short quiescent time at the inflection point was observed at $4.5 \mathrm{MW} / \mathrm{m}^{2}$ but not at $5.8 \mathrm{MW} / \mathrm{m}^{2}$. Thus, our results demonstrate that the highest HTC performance is obtained using a BBR under conditions where there is no intermittent emission of boiling sound; that is, when the growth and collapse frequency of the boiling bubbles matches the natural frequency of the BBR. To reveal differences between the observed frequency and the operating or natural frequency of the BBR, further experimental studies are needed.

(a)

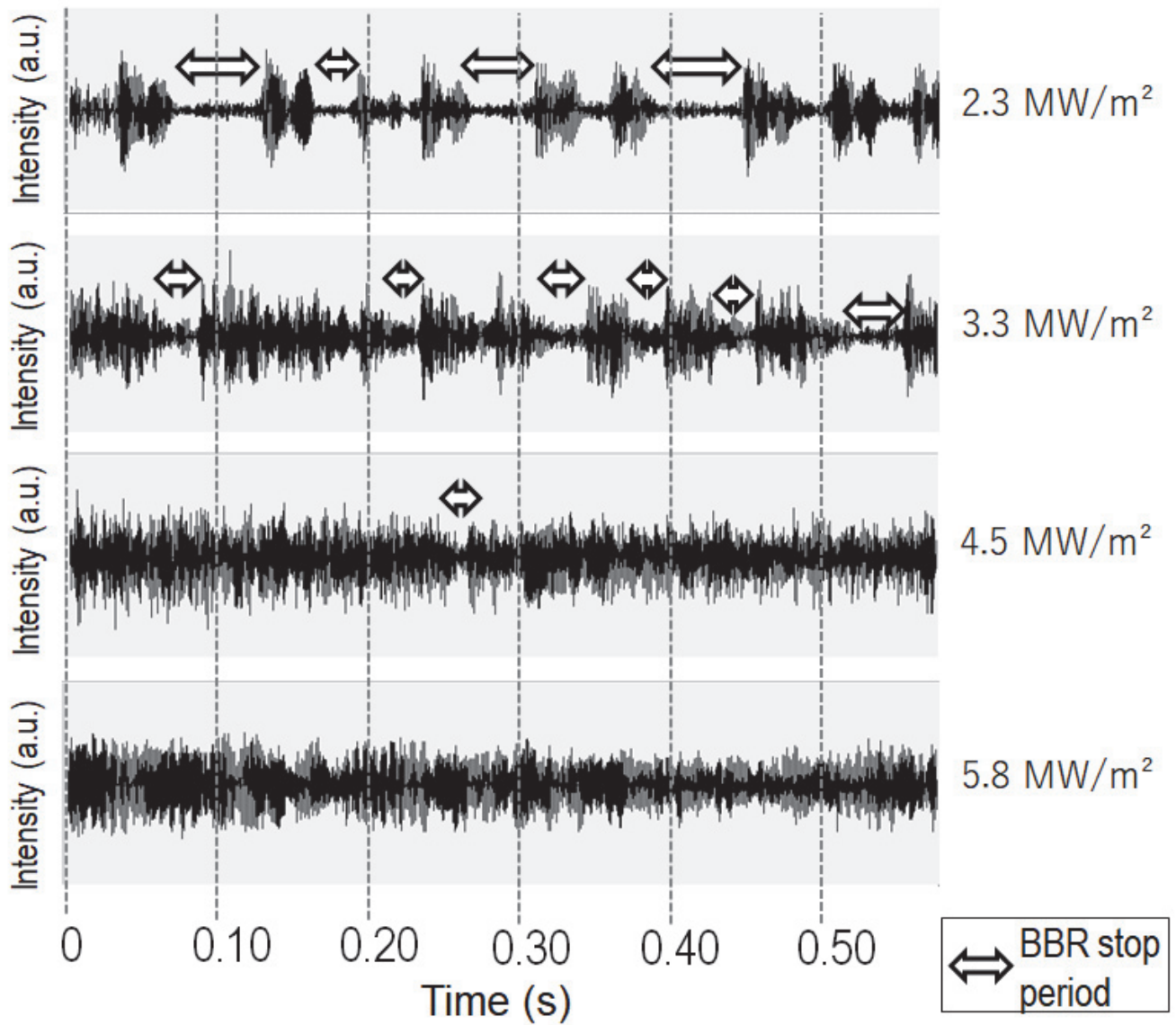

Fig. 10 Raw sound signals with a constant spacer height of $200 \mu \mathrm{m}$ at different heat fluxes. The vertical axis shows the intensity of the boiling sound. The double-headed white arrows show the quiescent time of the boiling bubble resonator.

\section{Conclusions}

We investigated BHT and the boiling sound for different gap heights between the heating surface and BBR in subcooled pool boiling tests. These experiments were conducted using de-ionized water at atmospheric pressure with a liquid subcooling of $50 \mathrm{~K}$. Self-excited vibration was achieved using our BBR, which was a thin brass plate fixed at both ends. We draw the following conclusions based on the experimental results:

(1) In the presence of the BBR, sound was generated owing to the collapse of the boiling bubbles. Although this is not necessarily due to the vibration of the BBR, the sound signal can be used to determine the optimal gap height. 
(2) Inversion of the boiling curve occurred when the gap height was $200 \mu \mathrm{m}$ for the BBR plate (with a width, vibrating length and thickness of $10 \mathrm{~mm}, 17.5 \mathrm{~mm}$ and $100 \mu \mathrm{m}$, respectively).

(3) The HTC with the BBR operating at a non-resonance frequency was lower than without the BBR.

(4) In the use of BBR, the heat flux that exhibits the highest HTC can be controlled by considering the balance between the bubble waiting time in the gap, the permeation of the subcooled liquid and the heat flux.

For a gap height of $200 \mu \mathrm{m}$, the wall superheat decreased by $25 \mathrm{~K}$ at $5.8 \mathrm{MW} / \mathrm{m}^{2}$ in contrast with $56 \mathrm{~K}$ at $5.6 \mathrm{MW} / \mathrm{m}^{2}$ without the BBR. Thus, we conclude that the BBR system is useful for improving the HTC at a target heat flux without decreasing the CHF when the gap height is optimally designed.

\section{Acknowledgement}

The authors would like to thank Emeritus Professor Koichi Suzuki (Sanyo-Onoda City University) for precious advice on the design of the heating block at high heat flux. We thank Adam Brotchie, PhD, from Edanz Group (https://enauthor-services.edanzgroup.com/ac) for editing a draft of this manuscript.

\section{References}

Betz, A. R., Xu, J., Qiu, H. and Attinger, D., Do surfaces with mixed hydrophilic and hydrophobic areas enhance pool boiling?, Applied Physics Letters, Vol. 97, No. 14 (2010), DOI: 10.1063/1.3485057.

Chu, K. H., Enright, R. and Wang, E. N., Structured surfaces for enhanced pool boiling heat transfer, Applied Physics Letters, Vol. 100, No. 24 (2012), DOI: 10.1063/1.4724190.

Chu, K. H., Soo Joung, Y., Enright, R., Buie, C. R. and Wang, E. N., Hierarchically structured surfaces for boiling critical heat flux enhancement, Applied Physics Letters, Vol. 102, No. 15 (2013), DOI: 10.1063/1.4801811.

Clough, R.W. and Penzien, J., Dynamics of Structures (1975), pp. 310-311, McGraw-Hill.

Fujita, Y., Ohta, H. and Uchieda, S., Heat transfer in nucleate boiling within a vertical narrow space, JSME international journal. Ser. 2, Fluids engineering, heat transfer, power, combustion, thermophysical properties, Vol. 31, No. 3 (1988), pp.513-519.

Hsu, C. C. and Chen, P. H., Surface wettability effects on critical heat flux of boiling heat transfer using nanoparticle coatings, International Journal of Heat and Mass Transfer, Vol. 55, No. 13-14 (2012), pp. 3713-3719.

Inada, S., Miyasaka, Y., Izumi, R. and Owase, Y., A study on Boiling Curves in Subcooled Pool Boiling (1st Report, An effect of liquid subcooling on local heat transfer), Transactions of JSME, Vol. 47, No. 417 (1981), pp. 852-861 (in Japanese).

Ivey, H. J. and Morris, D. J., Critical heat flux of saturation and subcooled pool boiling in water at atmospheric pressure, Proceedings of $3^{\text {rd }}$ International Heat Transfer Conference (1966), pp.129-142.

Jaikumar, A. and Kandlikar, S. G., Pool boiling inversion through bubble induced macroconvection, Applied Physics Letters, Vol. 110, No. 9 (2017), DOI: 10.1063/1.4977557.

Katto, Y. and Yokoya, S., Experimental Study of Nucleate Pool Boiling in Case of Making Interference-Plate Approach to the Heating Surface, Transactions of the Japan Society of Mechanical Engineers, Vol. 32, No. 238 (1966), pp. 948-958 (in Japanese).

Kandlikar, S. G., Enhanced Macroconvection mechanism with separate liquid-vapor pathways to improve pool boiling performance, Journal of Heat Transfer, Vol. 139, No. 5 (2017), DOI: 10.1115/1.4035247.

Kawakami, K., Sakamoto, S., Tanigawa, H., Yabuki, T. and Tsuruta, T., Observation of bubble behavior on heat transfer surface at MEB transition by confined space, Proceedings of Thermal Engineering Conference (2019), No.19-303, in Japanese.

Kim, B. S., Shin, S., Shin, S. J., Kim, K. M. and Cho, H. H., Micro-nano hybrid structures with manipulated wettability using a two-step silicon etching on a large area, Nanoscale Research Letters, Vol. 6 (2011), DOI: 10.1186/1556276X-6-333.

Kumar, G. U., Suresh, S., Kumar, C. S., Back, S., Kang, B. and Lee, H. J., A review on the role of laser textured surfaces on boiling heat transfer, Applied Thermal Engineering, Vol. 174 (2020), DOI: 10.1016/j.applthermaleng.2020.115274. 
Kutateladze, S.S., Heat transfer in condensation and boiling, U.S. Atomic Energy Commission. Translation series (1952), AEC-tr-3770.

Legay, M., Gondrexon, N., Le Person, S., Boldo, P. and Bontemps, A. Enhancement of heat transfer by ultrasound: review and recent advances, International Journal of Chemical Engineering, (2011), DOI: 10.1155/2011/670108.

Liang, G. and Mudawar, I., Review of pool boiling enhancement by surface modification, International Journal of Heat and Mass Transfer, Vol. 128 (2019), pp. 892-933.

Phan, H. T., Caney, N., Marty, P., Colasson, S. and Gavillet, J., Surface wettability control by nanocoating: the effects on pool boiling heat transfer and nucleation mechanism, International Journal of Heat and Mass Transfer, Vol. 52, No.23-24 (2009), pp. 5459-5471.

Rahman, M. M. and McCarthy, M., Boiling enhancement on nanostructured surfaces with engineered variations in wettability and thermal conductivity, Heat Transfer Engineering, Vol. 38, No.14-15 (2017), pp. 1285-1295.

Rahman, M. M., Olceroglu, E. and McCarthy, M., Role of wickability on the critical heat flux of structured superhydrophilic surfaces, Langmuir, Vol. 30, No. 37 (2014), pp. 11225-11234.

Sakamoto, S., Kawakami, K., Tanigawa, H. and Tsuruta, T., A study on transition process to MEB by changing boiling space, The Second Pacific Rim Thermal Engineering Conference, Hawaii, USA (2019), PRTEC-24083.

Sinha-Ray, S., Zhang, Y. and Yarin, A. L., Thorny devil nanotextured fibers: the way to cooling rates on the order of 1 $\mathrm{kW} / \mathrm{cm}^{2}$, Langmuir, Vol. 27, No. 1 (2011), pp. 215-226.

Sjölander, K. and Beskow, J., Wavesurfer-an open source speech tool, In Sixth International Conference on Spoken Language Processing (2000).

Smith, S. W., The scientist and engineer's guide to digital signal processing (1997), pp.220-222, California Technical Publishing.

Suzuki, K., Inagaki, F. and Hong, C, Subcooled Boiling in the Ultrasonic Field-On the Cause of Microbubble Emission Boiling, Heat Transfer Engineering, Vol. 32, No. 7-8 (2011), pp. 673-682.

Tang, J., Xie, G., Bao, J., Mo, Z., Liu, H. and Du, M., Experimental study of sound emission in subcooled pool boiling on a small heating surface, Chemical Engineering Science, Vol. 188 (2018), pp. 179-191.

Unno, N., Yuki, K., Taniguchi, J. and Satake, S., Boiling heat transfer enhancement by self-excited vibration, International Journal of Heat and Mass Transfer, Vol. 153 (2020), DOI: 10.1016/j.jheatmasstransfer.2020.119588.

Zhao, Y., Tsuruta, T. and Ji, C., Experimental study of nucleate boiling heat transfer enhancement in a confined space, Experimental thermal and fluid science, Vol. 28, No. 1 (2003), pp. 9-16.

Zhu, G., Sun, L., Tang, J., Mo, Z. and Liu H., A visualized study of micro-bubble emission boiling, International Communications in Heat and Mass Transfer, Vol. 59 (2014), pp. 148-157.

Zuber, N., Hydrodynamic aspect of boiling heat transfer, PhD Thesis, University of California, Los Angeles, CA, USA (1959), AECU-4439. 